\title{
PPMP, a novel tubulin-depolymerizing agent against esophageal cancer in patient-derived tumor xenografts
}

\author{
Yuqiao Sheng ${ }^{1,2,3, *}$, Kangdong Liu ${ }^{1,2,4, *}$, Qiong $\mathbf{W u}^{1,4, *}, \mathrm{Naomi}^{1} \mathbf{O i}^{2}$, Hanyong Chen ${ }^{2}$, \\ Kanamata Reddy', Yanan Jiang ${ }^{1}$, Ke Yao' ${ }^{2}$, Haitao Lí ${ }^{2}$, Wei $\mathbf{L i}^{2}$, Yi Zhang ${ }^{1,2,3,4}$, \\ Mohammad Saleem ${ }^{2}$, Wei-Ya Ma ${ }^{2}$, Ann M. Bode ${ }^{2}$, Ziming Dong ${ }^{1}$, Zigang Dong ${ }^{1,2,4}$ \\ ${ }^{1}$ Basic Medical College, Zhengzhou University, Zhengzhou, Henan, China \\ ${ }^{2}$ The Hormel Institute, University of Minnesota, Austin, Minnesota, USA \\ ${ }^{3}$ The First Affiliated Hospital, Zhengzhou University, Zhengzhou, China \\ ${ }^{4}$ China-US (Henan) Hormel Cancer Institute, ZhengZhou, Henan, China \\ *These authors contributed equally to this work
}

Correspondence to: Zigang Dong, e-mail: zgdong@hi.umn.edu

Ziming Dong, e-mail: Dongzm@zzu.edu.cn

Keywords: tubulin-depolymerizing agent, esophageal cancer, patient-derived tumor xenograft

Received: December 17, 2015

Accepted: April 10, 2016

Published: April 27, 2016

\section{ABSTRACT}

Esophageal cancer is one of the least studied and deadliest cancers worldwide with a poor prognosis due to limited options for treatment. Chemotherapy agents such as the microtubule-targeting compounds are the mainstay of palliation for advanced esophageal cancer treatment. However, the toxicity and side effects of tubulin-binding agents (TBAs) have promoted the development of novel, more potent but less toxic TBAs. Herein, we identified 2-[4-(3,4-dimethoxyphenyl)-3-methyl-1H-pyrazol-5yl]-5-[(2-methylprop-2-en-1-yI)oxy] phenol (PPMP) as a novel TBA for esophageal cancer treatment. PPMP markedly inhibited tubulin polymerization, and decreased viability and anchorage-independent growth of esophageal cancer cell lines, effects that were accompanied by G2/M arrest and apoptosis. Importantly, we produced patient-derived esophageal cancer xenografts to evaluate the therapeutic effect of PPMP in a setting that best mimics the clinical context in patients with esophageal cancer. Overall, we identified PPMP as a novel microtubule-destabilizing compound and as a new therapeutic agent against esophageal carcinoma.

\section{INTRODUCTION}

Esophageal cancer is the eighth most frequent malignancy and the sixth leading cause of cancer mortality worldwide [1]. According to the latest incidence and mortality global cancer statistics, 455,800 new cases of esophageal cancer were diagnosed and 400,200 deaths occurred in 2012 [2]. The incidence of esophageal cancer is extremely high in Eastern Asia and in Eastern and Southern Africa, and particularly in northern China [2,3]. The two main types of esophageal cancer, squamouscell carcinoma and adenocarcinoma, account for more than $90 \%$ of all cases of esophageal cancers [4]. For advanced esophageal cancer treatment, esophagectomy or radiotherapy is associated with poor prognosis owing to relatively late stage diagnosis and early systemic dissemination of disease, and chemotherapy is the mainstay of palliation in this setting $[1,5]$. In the use of single-agent or combination chemotherapy, tubulinbinding agents (TBAs), such as paclitaxel, docetaxel, vinorelbine, and vindesine, play an important role in esophageal cancer treatment [3].

In mammalian cells, microtubules are formed by polymerized $\alpha$ - and $\beta$-tubulin heterodimers, and are crucial for cell shape and maintenance of polarity, cell proliferation, cytokinesis, signaling, trafficking, and migration [6]. The essential role of microtubules and their dynamics in forming the mitotic spindle during cell division, which drives and mediates the replicated chromosomes from parent to offspring, has made them an important therapeutic target in cancer treatment for decades [7]. The major mechanism of TBAs' inhibition of 
cell proliferation is binding to microtubules and altering microtubule dynamics during the mitotic stage of the cell cycle [8].

Each of the microtubule processes, polymerization and depolymerization, is necessary for the proper execution of the cell division machinery, thereby segregating the microtubule-targeted antimitotic drugs into two major categories [9]. One category includes the microtubule-destabilizing agents, such as the vinca alkaloids, dolastatins, and colchicine and its analogues, which inhibit microtubule polymerization. Most of these agents bind at either the vinca domain or the colchicine domain of tubulin. Another category includes the microtubule-stabilizing agents, which enhance microtubule polymerization. Most of these agents bind to the same sites or to an overlapping taxoid-binding site on $\beta$-tubulin [7]. Although the TBAs, such as the vinca alkaloids and taxanes, have been used successfully for clinical anticancer therapy, many patients with cancer eventually develop acquired resistance to these agents [10]. Moreover, the toxicity and side effects of these existing agents drive the search for novel anti-microtubule drugs that are less toxic and less likely to result in resistance.

In the current study, by utilizing computational screening and molecular docking analysis, we identified 2-[4-(3,4-dimethoxyphenyl)-3-methyl-1H-pyrazol-5-yl]-5[(2-methylprop- 2-en-1-yl)oxy]phenol (PPMP) as a novel TBA. PPMP potently induced G2/M arrest and apoptosis and inhibited proliferation and growth of different human esophageal cancer cell lines. Most importantly, we evaluated the possible clinical use of PPMP by investigating its therapeutic effects in patient-derived xenografts (PDXs) of primary human esophageal cancer.

\section{RESULTS}

\section{PPMP inhibits growth of esophageal cancer cells}

From the computational screening results of the molecular docking analysis, we identified PPMP as a potential TBA compound (Figure 1A), which bound well with $\beta$-tubulin. To evaluate the effect of PPMP on the growth of human esophageal cancer cells, we analyzed cell viability in 3 esophageal cancer cell lines. PPMP inhibited growth of all 3 human esophageal cancer cell lines, KYSE30 (Figure 1B), KYSE450 (Figure 1C), and KYSE510 (Figure 1D), with $\mathrm{IC}_{50}$ values of $5.12 \mu \mathrm{M}$, $3.50 \mu \mathrm{M}$, and $2.85 \mu \mathrm{M}$, respectively.

\section{PPMP suppresses anchorage-independent growth of esophageal cancer cells}

To examine the effect of PPMP on anchorageindependent growth, human esophageal cancer cells were subjected to a soft agar assay. Data indicated that PPMP potently and dose-dependently, inhibited colony formation of all 3 esophageal cancer cell lines, KYSE30 (Figure 2A), KYSE450 (Figure 2B), and KYSE510 (Figure 2C), compared to untreated controls. These results show that PPMP exhibited strong antitumor efficacy against human esophageal cancer cell growth and deserves further investigation.

\section{PPMP triggers multinucleated cell formation and induces apoptosis in esophageal cancer cells}

To investigate the basis of PPMP's inhibitory effects, we used immunofluorescence microscopy to study the morphological phenotype of KYSE30 human esophageal cancer cells treated with PPMP. When KYSE30 cells were treated with PPMP at 2 or $5 \mu \mathrm{M}$ for $48 \mathrm{~h}$, flattened cells containing multiple nuclei were observed much more frequently compared with DMSO-treated controls (Figure 3A), suggesting a inhibition or delay in cell separation or cytokinesis. We next used Annexin V staining to measure the effect of PPMP on apoptosis in KYSE30, KYSE450, and KYSE510 cells (Figure 3B-3C). Results indicated that apoptosis was induced after exposure to PPMP $(5 \mu \mathrm{M})$ in all 3 esophageal cancer cell lines in a time-dependent manner. The cleavage of PARP and caspase 3 facilitates cellular disassembly and are considered to be markers for cells undergoing apoptosis. Consistent with the results of flow cytometry, our Western blot results demonstrated that in the presence of PPMP $(5 \mu \mathrm{M})$, cleaved PARP or caspase 3 increasingly appeared in KYSE30, KYSE450, and KYSE510 cells over time (Figure 3D). All these data suggest that PPMP treatment potently induces multinucleation and apoptosis in human esophageal cancer cells.

\section{PPMP induces G2/M cell cycle arrest of esophageal cancer cells}

Based on the previous multinucleation and apoptosis data, we then used flow cytometry to evaluate whether PPMP influences cell cycle phase of human esophageal cancer cells. When KYSE510 cells were treated with PPMP for $24 \mathrm{~h}$, we observed an increased number of cells in $\mathrm{G} 2 / \mathrm{M}$ phase that was accompanied by a decreased cell population in the G0/G1 phase of the cell cycle, which was also observed in KYSE30 and KYSE450 cells (Figure 4A-4B). Flow cytometry results indicated that a significant G2/M arrest was induced by PPMP treatment.

Based on the total mitotic index observed in esophageal cancer cells treated with PPMP, we analyzed the microtubule stabilization and chromosomal dynamics using an immunofluorescence assay. We used KYSE30 cells, which are the largest of the 3 esophageal cancer cell lines, and used antibodies to detect $\beta$-tubulin to evaluate microtubule structure and $\gamma$-tubulin to determine the number of centrioles. DMSO-treated control cells 
exhibited typical cell cycle progression (Figure 4C), whereas data showed a substantial increase in aberrant mitotic structures, including misaligned chromosomes and monopolar and multipolar spindles in KYSE30 cells (Figure 4D) treated with PPMP $(2 \mu \mathrm{M})$. These data provide evidence showing that PPMP treatment can lead to G2/M arrest in esophageal cancer cells, which is accompanied by abnormal microtubule structure and chromosome movement.

\section{PPMP inhibits tubulin polymerization}

To elucidate the mechanism by which PPMP affects microtubular structure in esophageal cancer cells, we focused our attention on the PPMP activity profile in ex vivo tubulin polymerization assays, which were performed with whole cells treated with various concentrations of PPMP or with taxol or combretastatin
A4 (CA4) as positive controls. Immunoblots were performed by separating the pellet " $\mathrm{P}$ ", containing polymerized tubulin, and the supernatant " $\mathrm{S}$ " fraction, containing depolymerized tubulin. When esophageal cancer cells were treated with increasing concentrations of PPMP, the amount of polymerized tubulin was decreased, which was accompanied by an increase in depolymerized tubulin (Figure 5A). This finding suggested that PPMP treatment affects microtubular structure by enhancing tubulin depolymerization.

We then were interested in determining whether PPMP interacts with microtubules directly in cellfree tubulin polymerization assays. We performed this assay using purified tubulin cocktails with GTP at $37^{\circ} \mathrm{C}$ for $60 \mathrm{~min}$ in the presence or absence of testing drugs, including PPMP, taxol, and CA4. The data indicated that without drug treatment, tubulin subunits selfassemble to form microtubules in a time-dependent
A<smiles>C=C(C)COc1ccc(-c2n[nH]c(C)c2-c2ccc(OC)c(OC)c2)c(O)c1</smiles>

2-[4-(3,4-dimethoxyphenyl)-3-methyl-1H-pyrazol-5yl]-5[(2-methylprop-2-en-1-yl)oxy]phenol (PPMP)

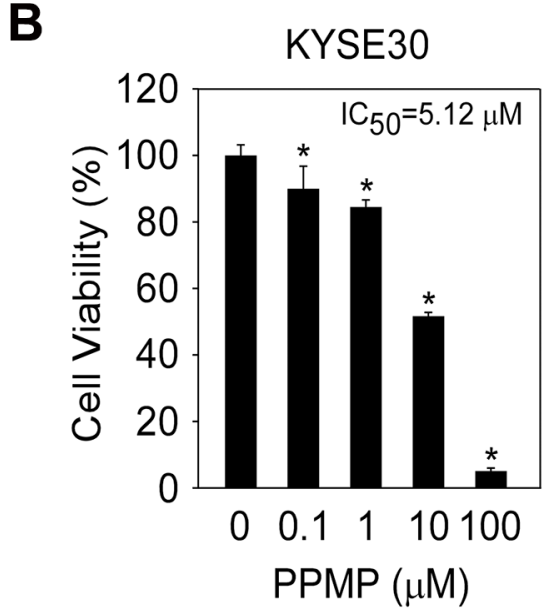

$\mathbf{D}$

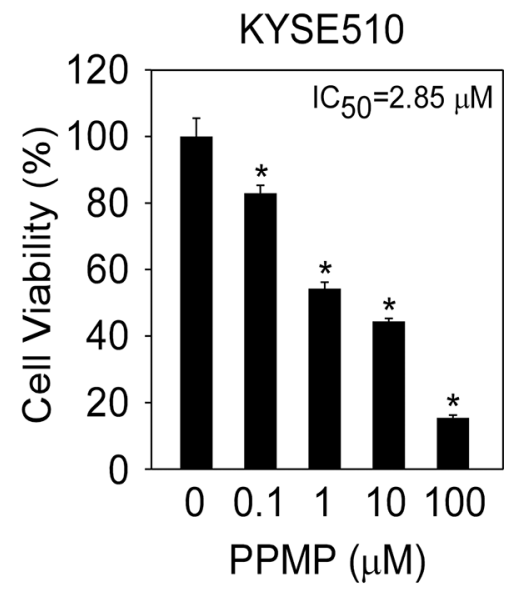

Figure 1: The structure of PPMP and its effect on viability of esophageal cancer cells. (A) Chemical structure of PPMP. Viability of human esophageal cancer cells was estimated by MTS assay in (B) KYSE30, (C) KYSE450, and (D) KYSE510 cancer cells. All esophageal cancer cells were treated for $48 \mathrm{~h}$ with various concentrations of PPMP. Data are shown as mean values \pm S.D. from 3 independent experiments conducted with triplicate samples. Statistical significance was determined by the Student's $t$-test $(* p<0.05$ vs. untreated group). 
manner (Figure 5B). Similar to the addition of CA4, in the presence of PPMP, a pronounced dose-dependent reduction in microtubule assembly was observed compared with the control, whereas taxol treatment led to a dramatic increase in tubulin polymerization (Figure 5B).

To determine whether PPMP could bind directly with tubulin subunits, we conducted ex vivo pulldown assays using PPMP-conjugated Sepharose 4B beads. The results indicated that PPMP-conjugated Sepharose $4 \mathrm{~B}$ beads bound to endogenous $\alpha$-tubulin and $\beta$-tubulin whereas no binding was observed with Sepharose 4B beads alone (Figure 5C). Molecular docking results predicted that PPMP interacted with $\beta$-tubulin by occupying the same binding site as colchicine (Figure 5D). The computational docking model results indicated that
PPMP can bind well at the colchicine binding site of tubulin and some important hydrogen bonds are formed between the compound and $\alpha$ - and $\beta$-tubulin (images were generated with UCSF Chimera program) [11]. This docking result shows an intermolecular interaction that provides a possible model depicting how PPMP binds with tubulin subunits and affects tubulin polymerization.

\section{In vivo antitumor efficacy of PPMP in human esophageal PDX tumor models}

To test the potential benefit of PPMP treatment in vivo, we utilized a human esophageal PDX tumor model. Surgically resected fresh tissue fragments from three different consenting patients were subcutaneously
A

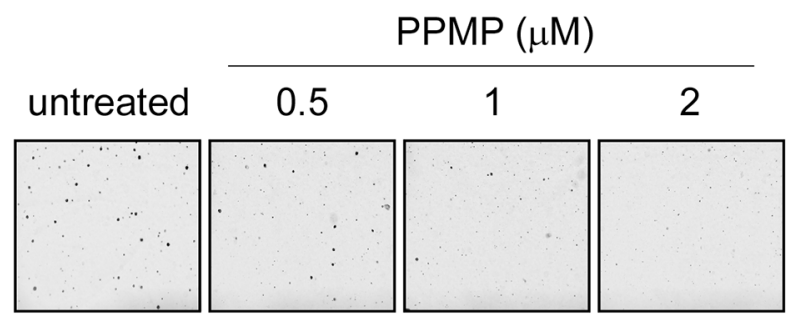

KYSE30

B
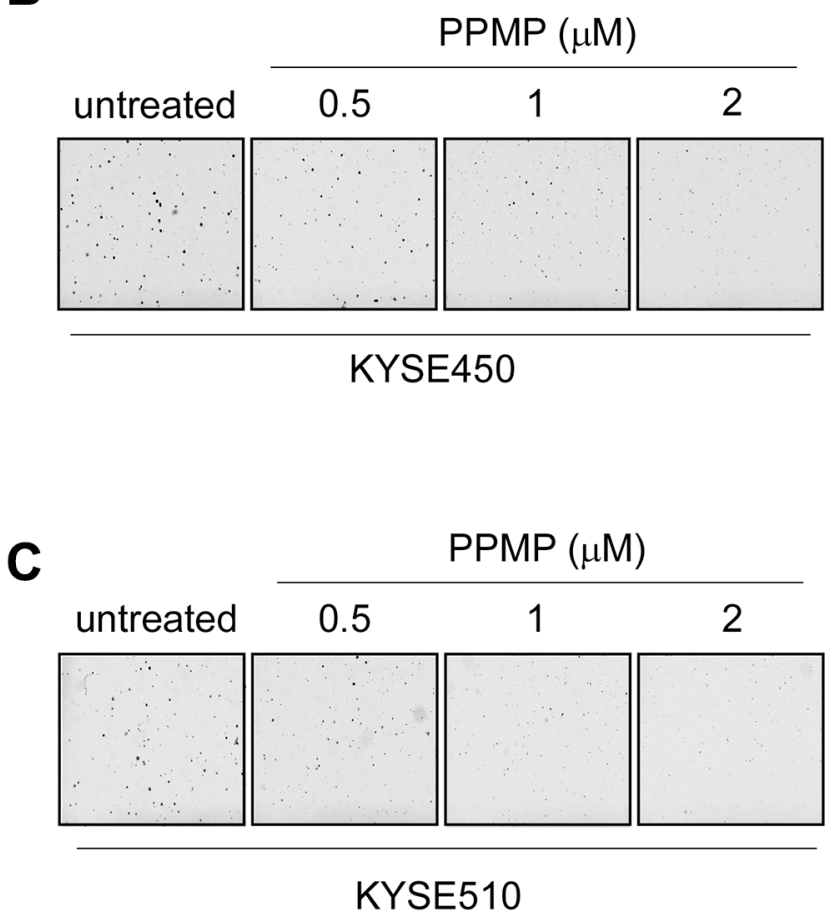
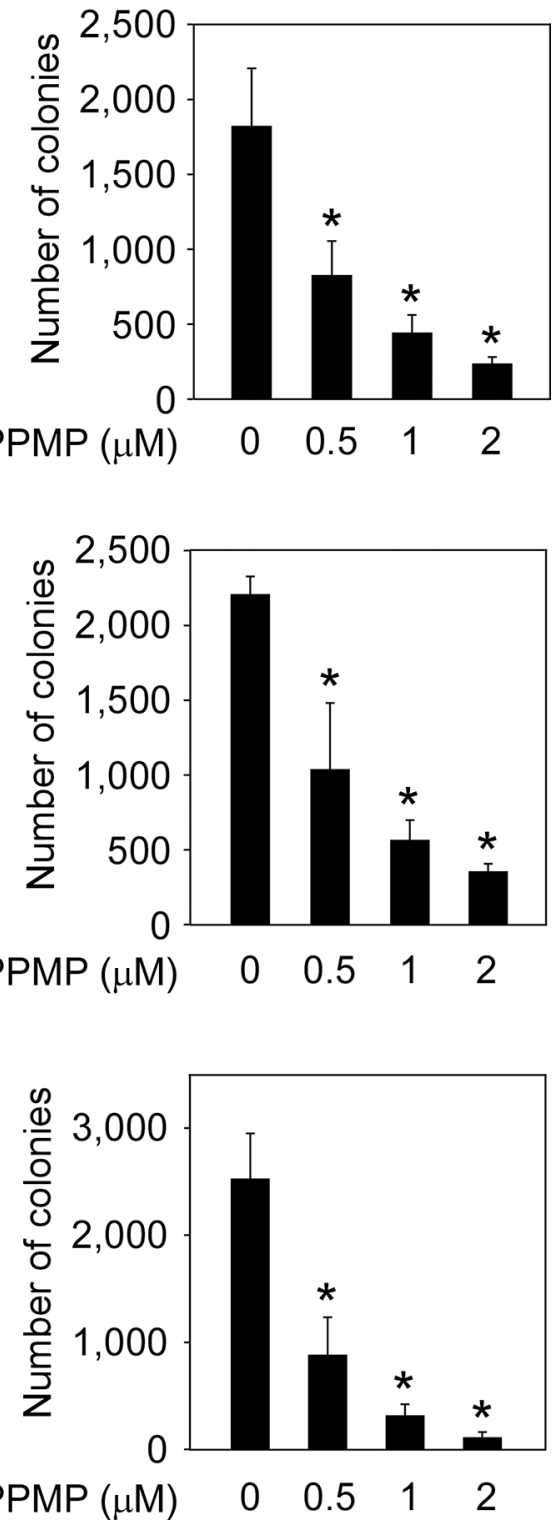

Figure 2: PPMP suppresses anchorage-independent soft agar growth of esophageal cancer cell lines. Three human esophageal cancer cell lines, (A) KYSE30, (B) KYSE450, and (C) KYSE510, were treated with PPMP and assayed for their ability to proliferate in soft agar. Multicellular colony formation was photographed at $25 \times$ magnification $\left({ }^{*} p<0.05\right.$ vs. untreated group). 
implanted in immunodeficient mice, and then expanded to generate 3 independent xenograft tumor lines (Figure 6A). A summary of the clinical characteristics for the 3 original tumors is provided in Table 1 . We selected three tumors having the same cancer grade and stage in order to maintain consistency and, thus, to facilitate statistical analysis. None of the PDX tumors received chemotherapy before surgery and subsequent implantation.

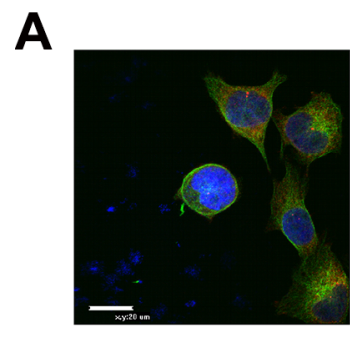

Untreated

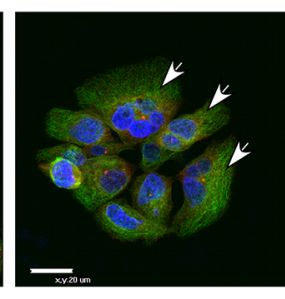

$2 \mu \mathrm{M}$

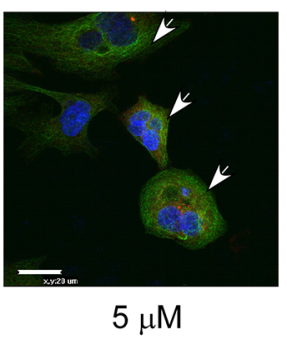

PPMP

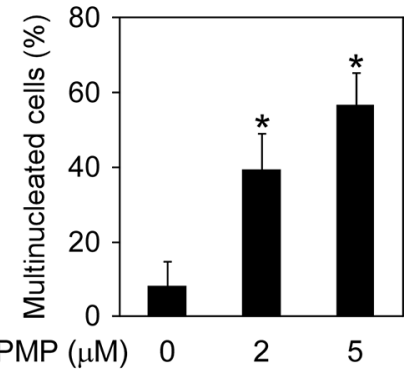

B
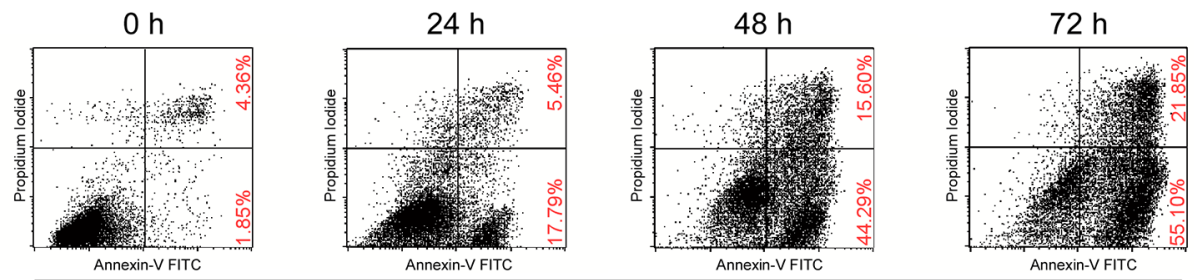

PPMP $(5 \mu \mathrm{M})$

C

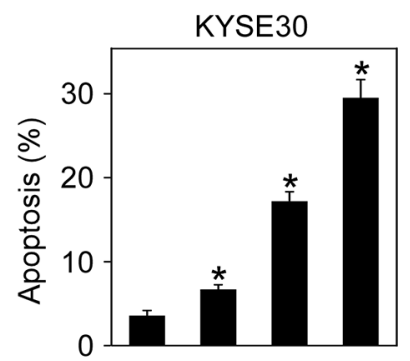

Time (h) $\quad 0 \quad 24 \quad 48 \quad 72$

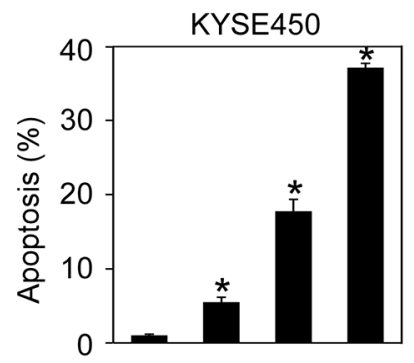

Time (h) $\quad 0 \quad 24 \quad 48 \quad 72$

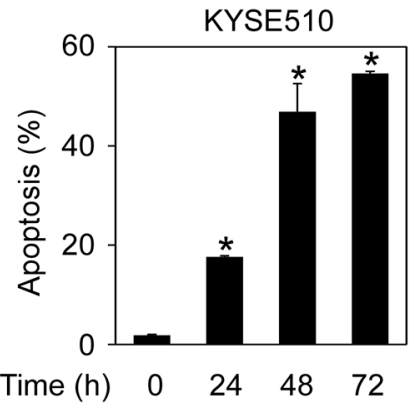

D

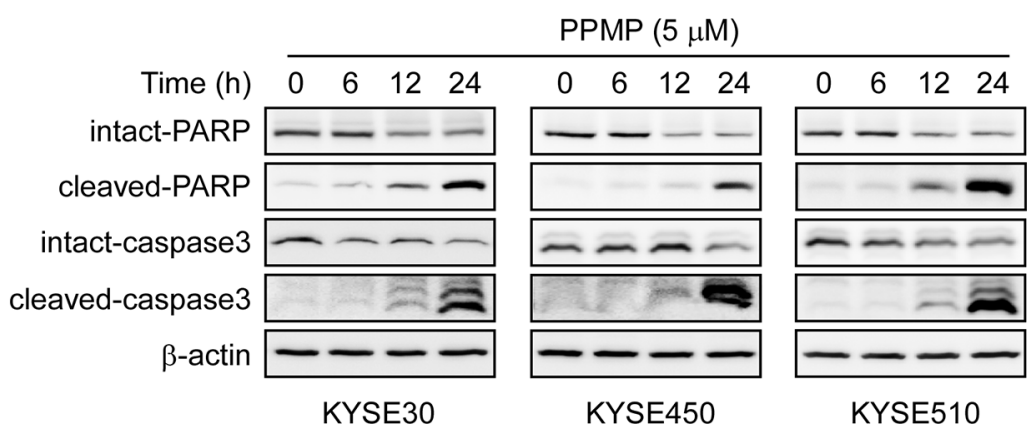

Figure 3: PPMP induces multinucleation and apoptosis in human esophageal cancer cells. (A) KYSE30 cells were treated with DMSO or PPMP (2 or $5 \mu \mathrm{M})$ for $24 \mathrm{~h}$ and then stained with anti- $\beta$-tubulin (green), anti- $\gamma$-tubulin (red), and DAPI (blue). Flat cells containing multiple nuclei are indicated (arrows). Scale bar indicates $20 \mu \mathrm{m}(\times 600)$. The percentage of multinucleated cells was quantified $\left({ }^{*} p<0.05\right.$ vs. untreated). (B) KYSE510 cells and each of (C) 3 human esophageal cancer cell lines were incubated with $5 \mu$ M PPMP for 0,24 , or $72 \mathrm{~h}$. Cells were collected and apoptosis was then detected using flow cytometry and Annexin V staining $\left({ }^{*} p<0.05\right.$ vs. 0 h). (D) Three esophageal cancer cell lines were treated with $5 \mu \mathrm{M}$ PPMP and harvested at $0,6,12$, or $24 \mathrm{~h}$, and then expression of apoptotic markers was detected by immunoblotting. 
A

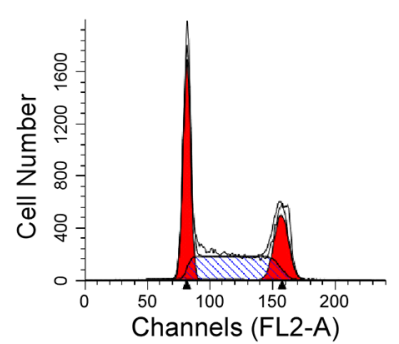

$\operatorname{PPMP}(0 \mu \mathrm{M})$

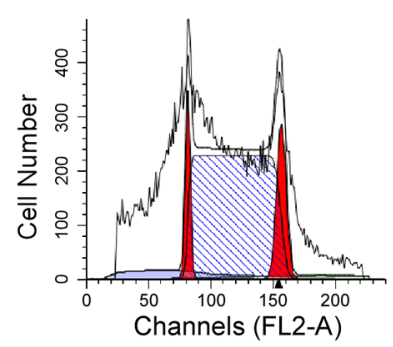

$\operatorname{PPMP}(1 \mu \mathrm{M})$

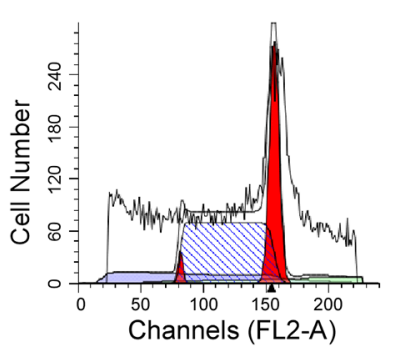

PPMP $(2 \mu \mathrm{M})$

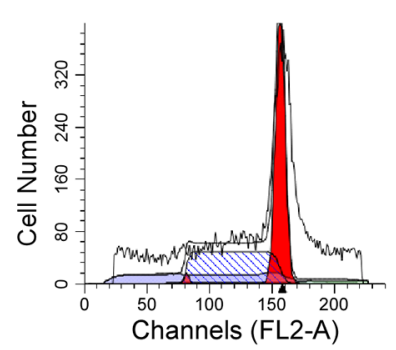

$\operatorname{PPMP}(5 \mu \mathrm{M})$

B

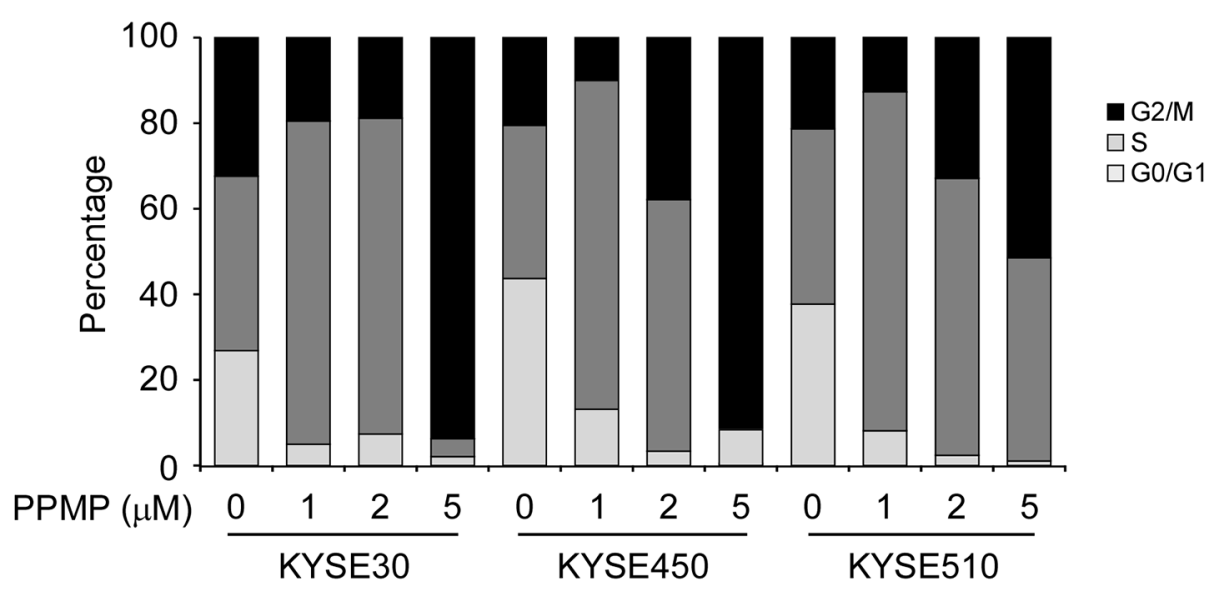

C
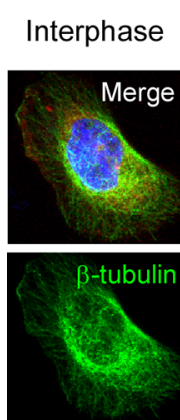

$\gamma$-tubulin
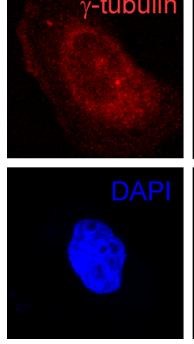
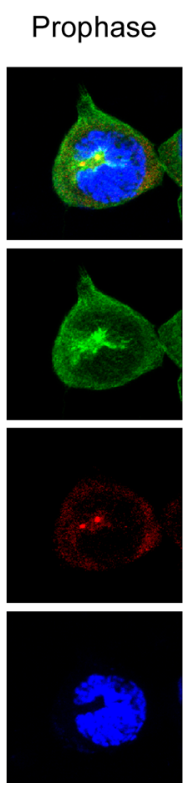
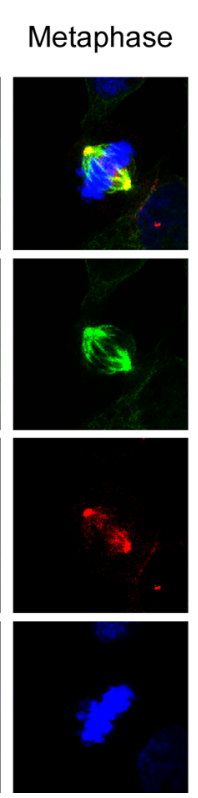

Anaphase Telophase
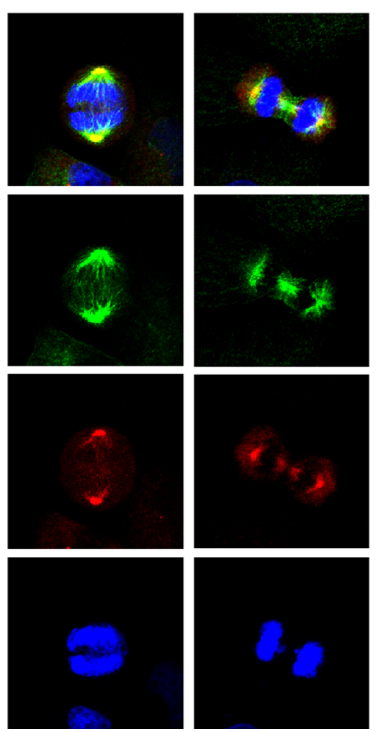

D

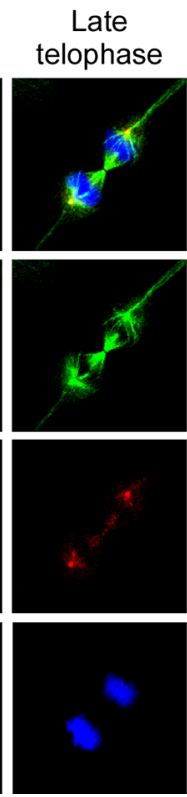

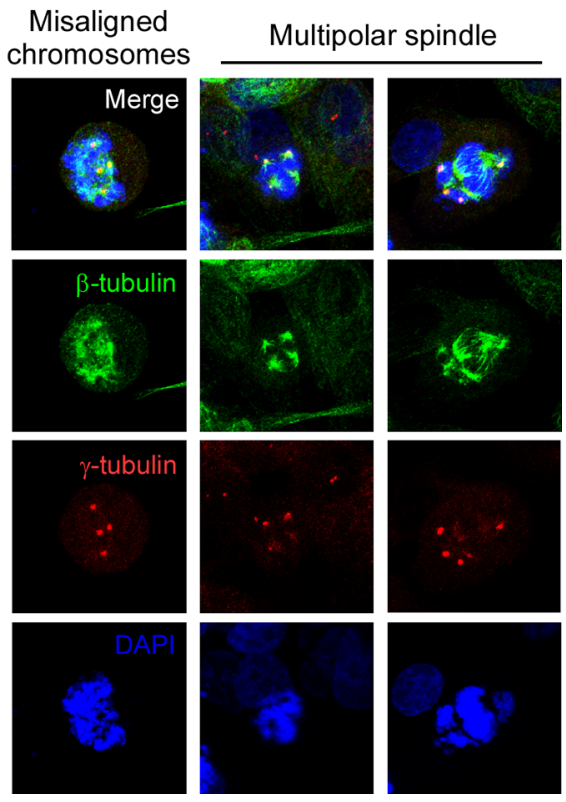

Figure 4: PPMP induces G2/M cell cycle arrest and affects the dynamics of microtubulin. Flow cytometry analysis of cell cycle was conducted using (A) KYSE510 cells and each of (B) 3 human esophageal cancer cell lines treated for $24 \mathrm{~h}$ with the indicated concentrations of PPMP. Cells were harvested and cell cycle was assessed by PI staining. Interphase and mitotic KYSE30 cells treated with (C) DMSO or (D) PPMP were observed by immunofluorescence. $\beta$-Tubulin, $\gamma$-tubulin, and DNA were stained with anti- $\beta$-tubulin (green), anti- $\gamma$-tubulin (red), and DAPI (blue), respectively. Merged images are also shown at the top, where co-localization of $\beta$-tubulin and $\gamma$-tubulin results in a yellow color. 
After the original tumor specimen was serially passaged to treatment phase 3 (P3), vehicle or different doses of PPMP was administered by intraperitoneal injection. Notably, at the end of the study, case EG8 was substantially more sensitive to either a high or low dose of PPMP treatment (tumor volume variation of $50 \mathrm{mg} / \mathrm{kg}$ PPMP treatment group vs. vehicle: $-89.9 \%$; $10 \mathrm{mg} / \mathrm{kg}$ PPMP vs. vehicle: $-56.3 \%$; Figure 6B). For case EG5, only the high dose of PPMP produced an obvious reduction in tumor volume $(-55.1 \%)$. Case EG2 tended to respond to PPMP treatment because tumor growth appeared to be delayed, but was not statistically significant. Importantly, no significant differences in body weights occurred among the three xenograft groups treated or not treated with PPMP (Figure 6C). All these in vivo data indicate that PPMP treatment provides positive efficacy without causing systemic toxicity.
A

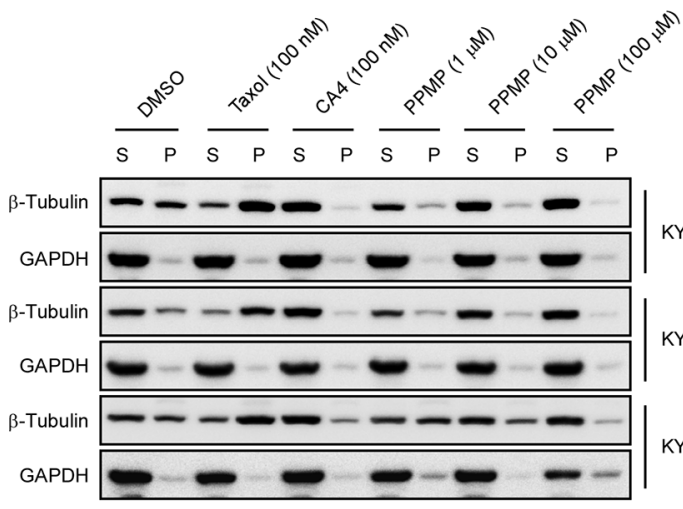

C

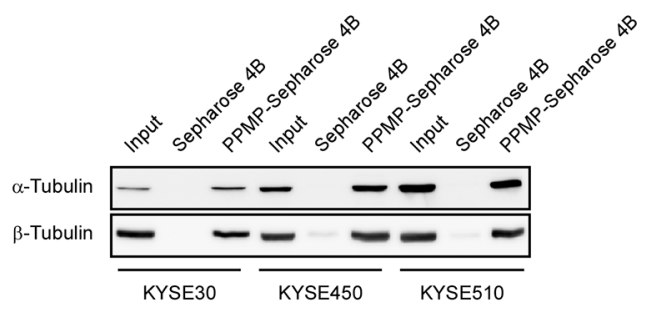

B

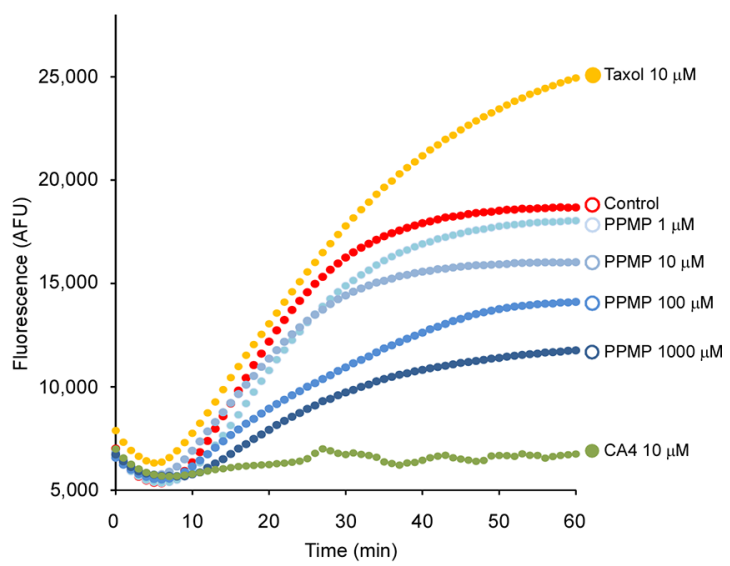

D $\alpha$-Tubulin $\quad \beta$-Tubulin

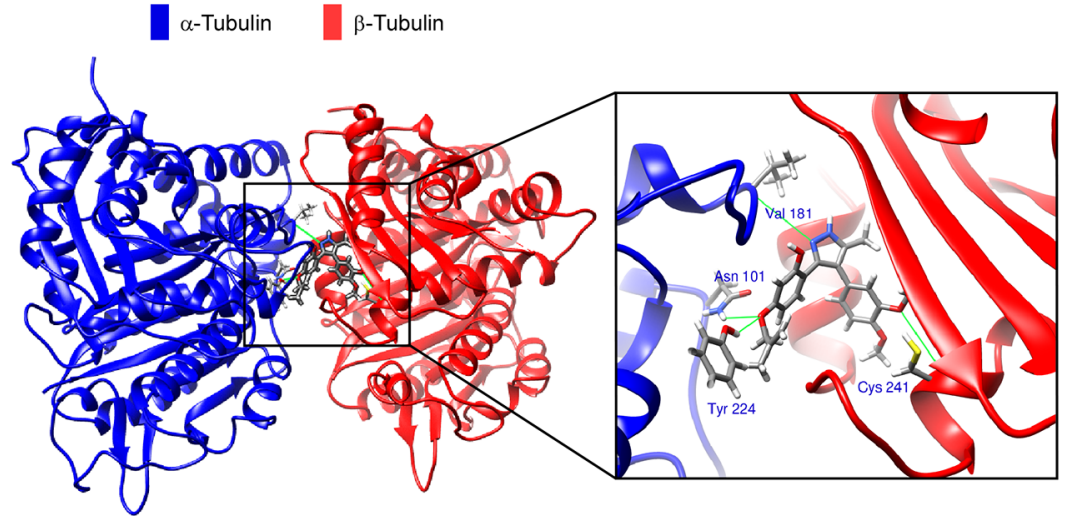

Figure 5: PPMP inhibits tubulin polymerization ex vivo and in vitro and also suppresses binding at the colchicinebinding site of tubulin. (A) PPMP inhibits tubulin polymerization ex vivo. Top to bottom, results for KYSE30, KYSE450, and KYSE510 cells. Pellet $(\mathrm{P})$ and supernatant $(\mathrm{S})$ fractions containing assembled and unassembled tubulin. Tubulin polymerization as a function of the dose of PPMP in all cell lines was detectable by the increase of tubulin in the supernatant fraction and its disappearance from the pellet. (B) PPMP inhibits the rate of in vitro tubulin polymerization. The in vitro tubulin polymerization assay was conducted using purified porcine brain tubulin. Controls were $\mathrm{H}_{2} \mathrm{O}, 10 \mu \mathrm{M}$ taxol, and $10 \mu \mathrm{M}$ CA4. The results are representative of 3 independent experiments. (C) Ex vivo binding of PPMP to $\alpha$-tubulin and $\beta$-tubulin was assessed by pull-down assays. Each of 3 esophageal cancer cell lysates was incubated with PPMP-Sepharose 4B beads or Sepharose 4B beads only. The protein expression was evaluated by Western blotting. (D) Computer docking model of PPMP and $\alpha$ - and $\beta$-tubulin. 


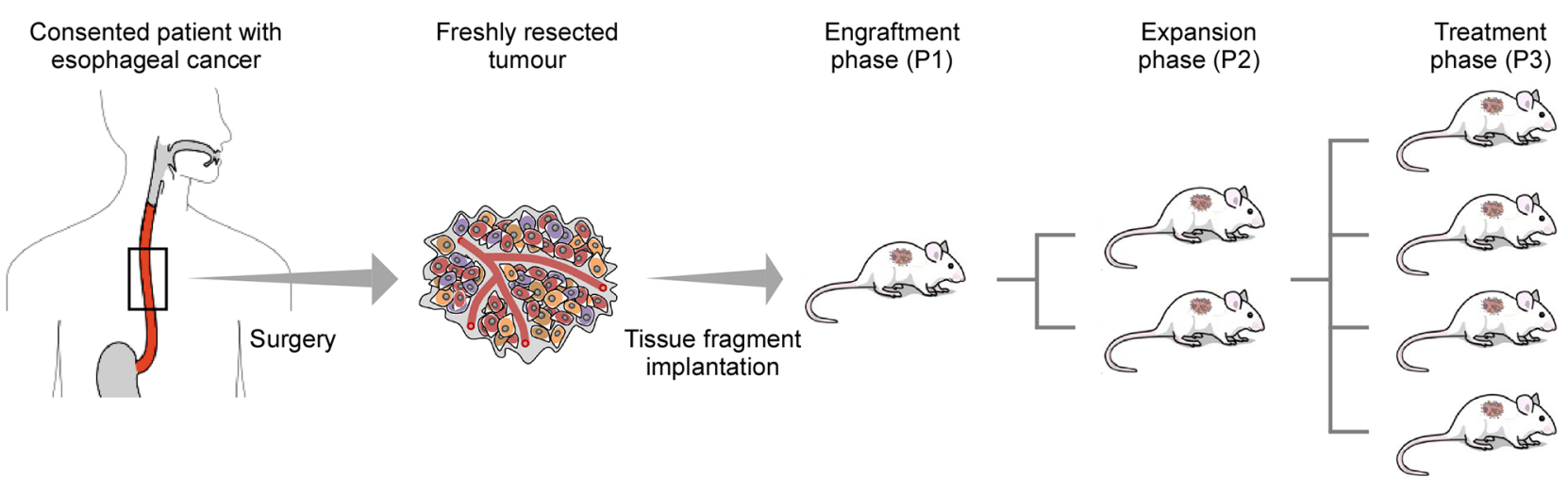

B
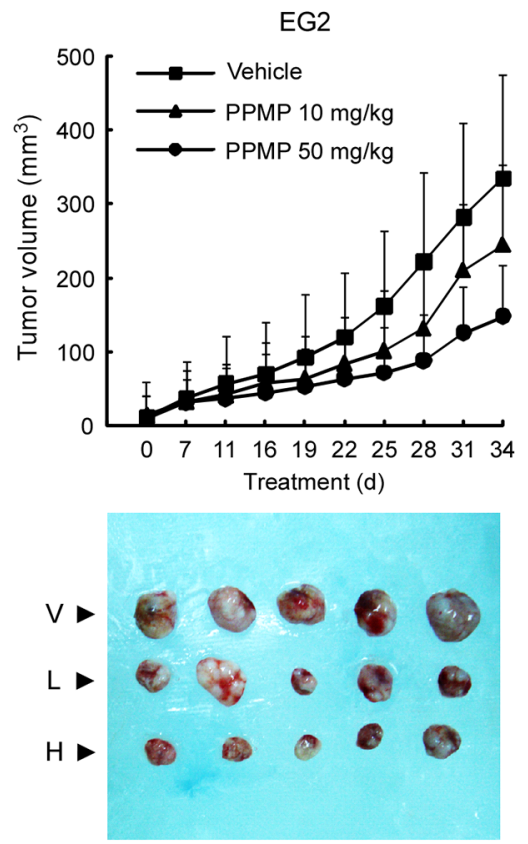

C

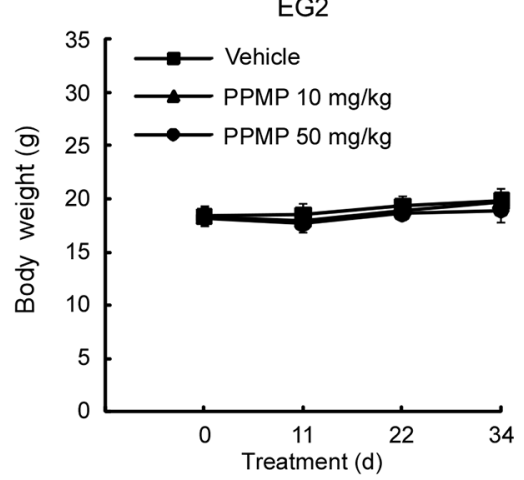

EG5
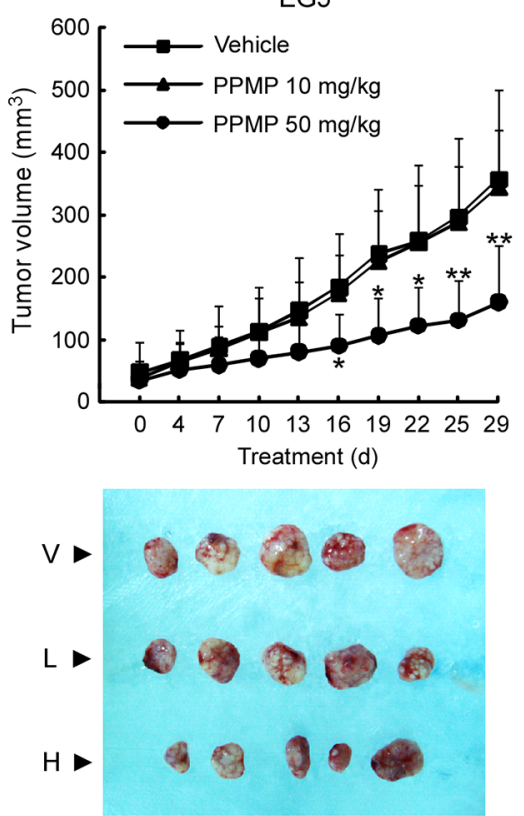

EG5

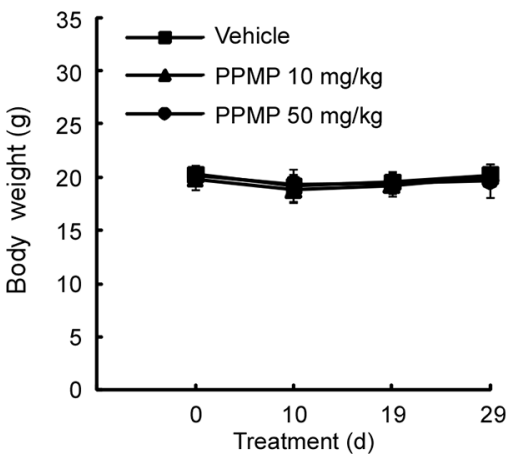

EG8
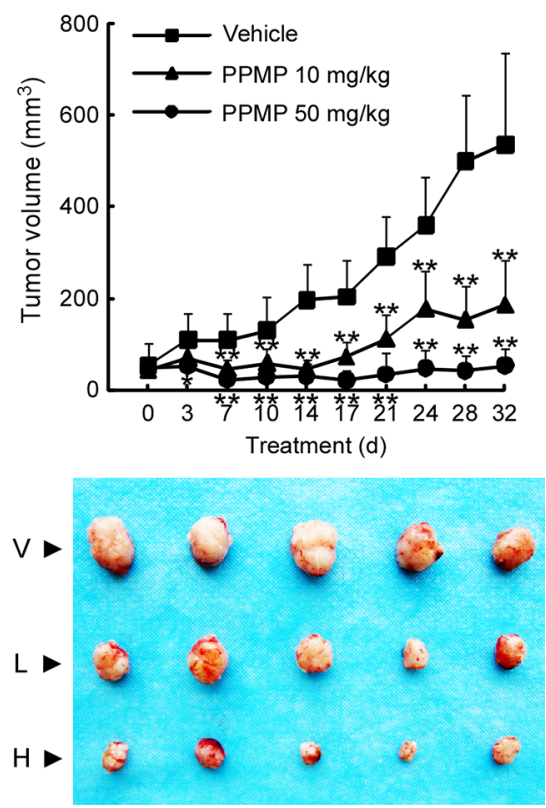

EG8

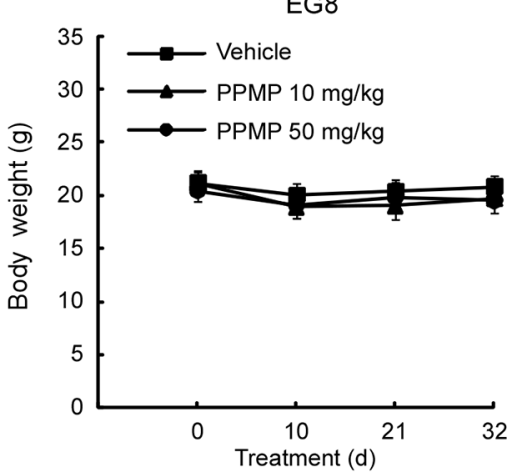

Figure 6: Establishment of the human esophageal patient-derived xenograft (PDX) tumor model and the antitumor efficacy of PPMP. (A) Schematic illustration of the protocol used for generation of a human esophageal PDX tumor model (details are described in Materials and Methods). (B) PPMP significantly inhibits tumor growth in a PDX tumor model compared to a vehicle-treated group. B-17 SCID mice each implanted with a different patient's tumor were divided into 3 groups. Mice implanted with EG2 (left, $n=8$ ), EG5

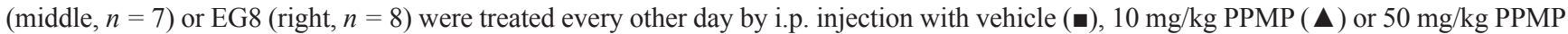
$(\bullet)$. Data are represented as mean values \pm S.D. The asterisks indicate significant differences determined by factorial ANOVA $(* p<0.05$ vs. vehicle; ${ }^{*} p<0.01$ vs. vehicle). Representative photographs show external appearance of tumors from 3 PDX models: V, vehicle; L, 10 mg/kg PPMP; H, 50 mg/kg PPMP. (C) Mouse body weight changes during PPMP treatment (EG2, left; EG5, middle; EG8, right). 
Table 1: Clinical characteristics of the origin used in PDX tumor models

\begin{tabular}{|c|c|c|c|c|c|c|c|}
\hline \multicolumn{1}{c}{ Model ID } & \multicolumn{1}{c}{ Gender } & \multicolumn{1}{c}{ Age (yrs) } & \multicolumn{1}{c}{ Source } & \multicolumn{1}{c}{ Histology } & \multicolumn{1}{c}{ Cancer grade } & \multicolumn{1}{c}{ Cancer stage } & \multicolumn{1}{c}{ Prior chemo } \\
\hline EG2 & Male & 64 & Primary & ESCC & IIa & T2N0M0 & No \\
\hline EG5 & Male & 61 & Primary & ESCC & IIa & T2N0M0 & No \\
\hline EG8 & Male & 63 & Primary & ESCC & IIa & T2N0M0 & No \\
\hline
\end{tabular}

ESCC: esophageal suamous-cell carcinoma.

T: tumor; N: lymph nodes; M: metastasis.

\section{DISCUSSION}

Because microtubules play an extremely important role in the process of mitosis, anti-microtubule agents, like vinca alkaloids and taxanes, have been used as an effective chemotherapeutic strategy for esophageal cancer treatment over the past several decades $[12,13]$. Because of the success of anti-microtubule agents in cancer therapy, developing novel agents directed against microtubules has become the focus, even as more selective approaches emerge [14]. Nonetheless, acquired resistance, significant toxicity and adverse side effects associated with existing TBAs reduce their efficacy $[15,16]$. Thus, in this context, identification of novel anti-microtubule drugs with enhanced cytotoxicity against tumor cells, limited toxicity to normal tissue and insensitivity to resistance mechanisms was our intent.

In the present study, we report the discovery of a novel microtubule-destabilizing compound referred to as PPMP. The result of ex vivo and in vitro tubulin polymerization assays clearly showed that PPMP markedly inhibited tubulin polymerization in a dose-dependent manner (Figure 5A-5B). Furthermore, our in vitro binding assay and computer modeling results predicted a model of the interaction of PPMP with $\alpha$ - and $\beta$-tubulin. PPMP binds with $\alpha$ - and $\beta$-tubulin at the same binding domain as colchicine (Figure 5C-5D). All these results indicate that PPMP is a novel microtubule-destabilizing compound. Cells treated with anti-microtubule agents usually exhibit G2/M arrest and apoptosis [17]. We examined the effect of PPMP on human esophageal cancer cells and results showed that PPMP markedly inhibited cell viability and anchorage-independent growth of all 3 esophageal cancer cell lines studied (Figures 1,2). The inhibition was associated with formation of multinucleated cells, accumulation of cells in the G2/M phase, and induction of apoptosis (Figures 3, 4). Similar to most TBAs that cause cancer cell death by driving them to apoptosis, necrosis or senescence, we postulated that PPMP treatment induces esophageal cancer cell death as a consequence of mitotic catastrophe $[18,19]$.
For in vivo system studies, the PDX model might be the most appropriate cancer model for studying the efficacy of treatment because it is more likely to reflect what happens in the clinic [20]. In contrast to xenografts generated from established cell lines or the genetically engineered mouse model, the PDX platform does not lead to genetic drift or is more genetically heterogeneous [21, 22]. In this study, we characterized the tumor growth responses to PPMP treatment of 3 different orthotopic esophageal cancer patient derived xenograft models for up to 34 days. Data show that PPMP effectively suppressed tumor growth without affecting mouse body weight (Figure 6). Notably, even though each of the 3 patients appears to exhibit similar clinical characteristics (Table 1), the sensitivity of each PDX tumor to PPMP was dissimilar. Therefore, further investigation of tumor cell heterogeneity, genetic background and tumor microenvironment of the original tumor will yield more specific strategies for clinical application of PPMP.

Currently, colchicine binding site inhibitors (CBSI) have been extensively studied. However, such agents have not yet reached the commercial phase for cancer therapy. We are eager to find a better CBSI having potential in clinical practice. Moreover, according to the literature, CBSIs like combretastatins and N-acetylcolchicinol-Ophosphate, have undergone considerable development as vascular-disrupting agents (VDAs) [23, 24]. The vasculature inside a solid tumor should be a superb therapeutic target. VDAs collapse the vascular structure, depriving the tumor of nutrients and oxygen that are needed for the tumor to survive [25]. As a potential CBSI, PPMP exerts its potent effects on the microtubule cytoskeleton and therefore might also produce rapid disruption of tumor blood flow. To improve our knowledge of this drug, further studies will be required to determine whether PPMP acts as a VDA or has additional targets in esophageal cancer or other cancer types.

Collectively, we provided evidence showing that PPMP suppresses the tumor growth of orthotopic PDX human esophageal tumors, a model that best mimics 
the clinical context. In conclusion, our in vitro studies and preclinical platform identified PPMP as a novel microtubule depolymerize and mitotic blocker for the chemotherapy of esophageal cancer.

\section{MATERIALS AND METHODS}

\section{Chemicals and reagents}

We synthesized PPMP in-house by consulting a reported protocol and adding some modification [26]. Taxol was purchased from Selleck Chemicals (Houston, TX), and combretastatin A4 (CA4) was from SigmaAldrich Co. (St. Louis, MO). Basal Medium Eagle (BME), L-glutamine, gentamicin, penicillin, Eagle's Minimum Essential Medium (MEM), F-12K medium, and RPMI1640 medium were all from Life Technologies, Inc. (Grand Island, NY). Fetal bovine serum (FBS) was obtained from Gemini Bio-Products (West Sacramento, CA). Primary antibodies against $\alpha$-tubulin, $\beta$-actin or GAPDH were from Santa Cruz Biotechnology, Inc. (Santa Cruz, CA) and the other antibodies were purchased from Cell Signaling Technology (Danvers, MA) unless otherwise specified. CNBr-activated Sepharose ${ }^{\mathrm{TM}} 4 \mathrm{~B}$ beads were from GE Healthcare Biosciences (Pittsburgh, PA).

\section{Cell culture}

The KYSE30, KYSE450 and KYSE510 human esophageal cancer cell lines were from ATCC. All cells were cultured with antibiotics at $37^{\circ} \mathrm{C}$ in a humidified $5 \% \mathrm{CO}_{2}$ incubator and maintained for a maximum of 2 months (10 passages). Cells were cytogenetically tested and authenticated before freezing. All cell lines were cultured in 45\% F-12K medium/45\% RPMI-1640 medium supplemented with $10 \%$ FBS.

\section{MTS assay}

Esophageal cancer cells $\left(1 \times 10^{3}\right.$ cells per well $)$ were seeded onto 96-well plates and treated or not treated with different concentrations of PPMP for measuring proliferation. After incubation for $48 \mathrm{~h}, 20 \mu \mathrm{l}$ of CellTiter96 Aqueous MTS reagent (Promega Corporation, Madison, WI) were added to each well and then cells were incubated for $90 \mathrm{~min}$ at $37^{\circ} \mathrm{C}$ in a $5 \% \mathrm{CO}_{2}$ incubator. The optical density (OD) was measured at $490 \mathrm{~nm}$.

\section{Anchorage-independent cell growth assay}

Esophageal cancer cells $\left(8 \times 10^{3}\right.$ cells per well) were suspended in a top layer of BME/10\% FBS $/ 0.33 \%$ agar with various concentrations of $\operatorname{PPMP}(0,0.5,1$ or $2 \mu \mathrm{M})$ and plated on a bottom layer of $\mathrm{BME} / 10 \% \mathrm{FBS} / 0.5 \%$ agar with the indicated concentrations of PPMP in each well of six-well plates. After incubation for 1 to 2 weeks at $37^{\circ} \mathrm{C}$ in a $5 \% \mathrm{CO}_{2}$ incubator, colonies were counted under a microscope using the Image-Pro Plus software (v.6) program (Media Cybernetics. Rockville, MD).

\section{Flow cytometry for analysis of apoptosis and cell cycle}

For analysis of apoptosis, cancer cells $\left(2 \times 10^{5}\right.$ cells per well) were seeded into six-well plates and cultured for $24 \mathrm{~h}$, then exposed to $5 \mu \mathrm{M}$ PPMP for $0,24,48$ or $72 \mathrm{~h}$. Cells were trypsinized and washed twice with cold PBS and then resuspended with phosphate-buffered saline and incubated for $5 \mathrm{~min}$ at room temperature with annexin V-FITC plus propidium iodide. Cells were analyzed using a FACSCalibur flow cytometer (BD Biosciences, San Jose, CA). For cell cycle analysis, cancer cells $\left(2 \times 10^{5}\right.$ cells per well) were plated in 60-mm plates and cultured for $24 \mathrm{~h}$, then exposed to $0,1,2$ or $5 \mu \mathrm{M}$ PPMP for $24 \mathrm{~h}$. Cells were harvested and washed twice with PBS and fixed with cold $70 \%$ ethanol overnight at $-20^{\circ} \mathrm{C}$. Stained cells were detected and quantified using a FACSort flow cytometer (BD Biosciences, San Jose, CA).

\section{Western blot}

Sample protein concentration was determined using a protein assay kit (Bio-Rad Laboratories, Inc. Hercules, CA). Total proteins (20 to $100 \mu \mathrm{g}$ ) were separated by SDSPAGE and transferred onto a polyvinylidene difluoride (PVDF) membrane (Millipore, Billerica, MA). After blocking in 5\% milk, the membranes were probed with specific primary antibodies overnight at $4{ }^{\circ} \mathrm{C}$, washed 3 times with TBS-Tween 20, and then incubated with a horseradish peroxidase (HRP) conjugated secondary antibody at room temperature $1 \mathrm{~h}$ for hybridization. The protein bands were visualized with a chemiluminescence reagent (GE Healthcare Biosciences, Pittsburgh, PA).

\section{Immunofluorescence assay}

This study was conducted on KYSE30 cells in 4-chamber slides. After treatment with dimethyl sulfoxide (DMSO) or PPMP ( 2 or $5 \mu \mathrm{M}$ ) for $24 \mathrm{~h}$, an asynchronous population of cancer cells were washed with PBS, fixed with $4 \%$ formaldehyde for $10 \mathrm{~min}$, followed by blocking with $10 \% \mathrm{FBS} / \mathrm{PBS}(\mathrm{v} / \mathrm{v})$ for $20 \mathrm{~min}$. Cells were then incubated with primary antibodies, including $\beta$-tubulin rabbit $\mathrm{mAb}(1: 100)$ or $\gamma$-tubulin mouse mAb (1:200) overnight at $4^{\circ} \mathrm{C}$. After washing with $\mathrm{PBS}$, secondary antibodies, including Alexa Fluor 488 rabbit IgG conjugate or Alexa Fluor 594 mouse IgG conjugate were applied. Nuclei were then demarcated using 4',6-diamidino-2phenylindole (DAPI, Pierce Biotechnology, Inc.) for $30 \mathrm{~min}$ at room temperature. Samples were evaluated by a fluorescence microscope system (Leica, Mannheim, Germany). 


\section{Tubulin polymerization assay ex vivo and in vitro}

For the ex vivo tubulin polymerization assay, tubulin depolymerization was measured using a modified version of a method originally documented by Minotti, et al. [27]. Briefly, esophageal cancer cells were grown in $60-\mathrm{mm}$ plates in the presence or absence of the indicated concentrations of drugs for $24 \mathrm{~h}$. Then the cells were pelleted, washed twice with PBS, and disrupted with $100 \mu 1$ hypotonic buffer [0.5\% NP40, 2 mM EGTA, $1 \mathrm{mM}$ $\mathrm{MgCl}_{2}, 20 \mathrm{mM}$ Tris-HCl (pH 6.8), and a protease inhibitor mixture] for $10 \mathrm{~min}$ at room temperature. Lysates were then centrifuged at $13,000 \mathrm{rpm}$ for $15 \mathrm{~min}$ at $4^{\circ} \mathrm{C}$, and the soluble fraction containing depolymerized tubulin was separated from the insoluble fraction containing polymerized tubulin. Each fraction was mixed with equal volumes of $6 \times$ SDS loading buffer, heated for $10 \mathrm{~min}$ at $95^{\circ} \mathrm{C}$, and analyzed by Western blot. For the in vitro tubulin polymerization assay, performance was monitored using a tubulin polymerization kit (Cytoskeleton, Denver, $\mathrm{CO}$ ). Purified porcine brain tubulin was resuspended on ice in ice-cold buffer $[2 \mathrm{mM} \mathrm{MgCl}, 0.5 \mathrm{mM}$ EGTA, $0.5 \mathrm{mM}$ EGTA, $2 \mathrm{mM} \mathrm{MgCl}$, $1 \mathrm{mM}$ GTP, $15 \%$ glycerol, and $80 \mathrm{mM}$ PIPES (pH 6.9)]. The $100 \mu \mathrm{L}$ suspension was then aliquoted into a half-area 96 -well plate with $5 \mu \mathrm{L}$ of the indicated concentrations of different drugs at $37^{\circ} \mathrm{C}$. Fluorescence intensity was determined by excitation at $355 \mathrm{~nm}$ and emission at $460 \mathrm{~nm}$ every min for $1 \mathrm{~h}$ using the Synergy 2 Multi-Mode Reader (BioTek Instruments, Winooski, VT)

\section{Preparation of PPMP-conjugated sepharose 4B beads}

PPMP-conjugated Sepharose 4B beads were prepared following the protocol provided by $\mathrm{GE}$ Healthcare Biosciences. Briefly, Sepharose 4B dried powder $(0.3 \mathrm{~g})$ was suspended in $1 \mathrm{mM} \mathrm{HCl}$ and a $40 \%$ $\mathrm{DMSO} / \mathrm{H}_{2} \mathrm{O}(\mathrm{v} / \mathrm{v})$-coupled solution $\left[0.1 \mathrm{~mol} / \mathrm{L} \mathrm{NaHCO}_{3}\right.$ (pH 8.3) and $0.5 \mathrm{M} \mathrm{NaCl}$ ] was then mixed with compound PPMP $(1.5 \mathrm{mg})$ and rotated at $4^{\circ} \mathrm{C}$ overnight. The beads were transferred to $0.1 \mathrm{M}$ Tris- $\mathrm{HCl}$ buffer $(\mathrm{pH} 8.0)$ and again rotated overnight at $4^{\circ} \mathrm{C}$. Finally, the beads were washed with $0.1 \mathrm{M}$ acetate buffer ( $\mathrm{pH} 4.0$ ) containing $0.5 \mathrm{M} \mathrm{NaCl}$ three times followed by washing once with $0.1 \mathrm{M}$ Tris- $\mathrm{HCl}(\mathrm{pH} \mathrm{8.0)}$ ) containing $0.5 \mathrm{M} \mathrm{NaCl}$.

\section{Pulldown assays}

PPMP-conjugated Sepharose 4B beads or Sepharose $4 \mathrm{~B}$ beads only ( $100 \mu 1,50 \%$ slurry) were incubated with a KYSE30, KYSE450, or KYSE510 cell lysate $(500 \mu \mathrm{g})$ in reaction buffer [5 mM EDTA, $1 \mathrm{mM}$ DTT, $150 \mathrm{mM}$ $\mathrm{NaCl}, 0.01 \%$ NP40, $50 \mathrm{mM}$ Tris- $\mathrm{HCl}$ (pH 7.5), $0.02 \mathrm{mM}$ phenylmethylsulfonyl fluoride, $2 \mathrm{mg} / \mathrm{ml}$ bovine serum albumin, and a protease inhibitor mixture] with gentle rocking overnight at $4^{\circ} \mathrm{C}$. After incubation, the beads were washed 5 times with washing buffer [ $5 \mathrm{mM}$ EDTA, $1 \mathrm{mM}$ DTT, $150 \mathrm{mM} \mathrm{NaCl}, 0.01 \%$ NP40, $50 \mathrm{mM}$ Tris- $\mathrm{HCl}(\mathrm{pH}$ 7.5)], and proteins bound to the beads were boiled and analyzed by Western blotting.

\section{Computer modeling}

To identify a new TBA and to study the interaction of candidate compounds with tubulin, we performed an extensive molecular docking analysis. First the tubulin X-ray crystal structure with a resolution of $2.30 \AA$ [28] was downloaded from the PDB Bank [29]. Then the structure was prepared under the standard procedure of Protein Preparation Wizard in Schrödinger Suite 2014 [30]. Hydrogen atoms were added consistent with a $\mathrm{pH}$ of 7 and all water molecules were removed. Finally, a receptor grid of tubulin was generated based on the colchicine-binding site for studying docking. After PPMP was chosen as the candidate TBA, it was prepared under the program of LigPrep of Schrödinger Suite 2014 by default parameters for screening. Docking was accomplished using the program Glide by default parameters under the extra precision (XP) mode. Herein, we can get the best-docked representative structures.

\section{Patient sample selection and annotation}

Human tissue collection and use protocols were approved by the ethics committee of Zhengzhou University, Zhengzhou, Henan, China. Esophageal tumor samples were obtained from 3 patients who were informed and provided written consent. Patients were treated with surgery at the First Affiliated Hospital of Zhengzhou University (Zhengzhou, Henan, China). Pathologic and clinical data were entered and maintained in our prospective database.

\section{PDX establishment}

Based on the guidelines approved by the ethics committee of Zhengzhou University, fresh tumor tissue fragments were collected and transferred at $4{ }^{\circ} \mathrm{C}$ in FBS-free RPMI-1640 medium with antibiotics. Within $2 \mathrm{~h}$ of surgical resection, tumor tissues were trimmed, cut into 3-5 $\mathrm{mm}$ sizes and implanted subcutaneously in anesthetized 6 to 8 week old female C.B-17 severe combined immunodeficient (SCID) mice (Vital River Laboratories Co., Ltd., Beijing, China). Once mass formation reached about $1500 \mathrm{~mm}^{3}$, mice of this first generation of xenografts (named P1) were sacrificed and the tumors were passaged and expanded for 2 more generations (named P2 and P3). When P3 tumors reached an average volume of $50 \mathrm{~mm}^{3}$, mice were divided into 3 groups ( $n=7-8$ mice per group) and treated with vehicle, 10 or $50 \mathrm{mg} / \mathrm{kg}$ PPMP, respectively, every 
other day by intraperitoneal (i.p.) injection. PPMP was dissolved in dimethyl sulfoxide (DMSO; 5\%) and polyethylene glycol (PEG400; 5\%) in PBS. Tumor volume [length $\times$ width $\times$ height $\times 0.52$ ] and body weight were recorded twice a week.

\section{Statistical analysis}

As necessary, all quantitative data are expressed as mean values \pm standard deviation (S.D.) or standard error (S.E.). The Student's $t$-test or one-way ANOVA was conducted to determine statistically significant differences. A probability value of $p<0.05$ was used as the criterion for statistical significance.

\section{ACKNOWLEDGMENTS AND FUNDING}

This work was supported by The Hormel Foundation and grants from the National Institutes of Health CA166011, CA172454, CA187027, CA196639, R37 CA081064, and from the National Natural Science Foundation of China 81502628.

\section{CONFLICTS OF INTEREST}

The authors declare no conflicts of interest.

\section{REFERENCES}

1. Zhang Y. Epidemiology of esophageal cancer. World J Gastroenterol. 2013; 19:5598-5606.

2. Torre LA, Bray F, Siegel RL, Ferlay J, Lortet-Tieulent J, Jemal A. Global cancer statistics, 2012. CA Cancer J Clin. 2015; 65:87-108.

3. Ilson DH. Esophageal cancer chemotherapy: recent advances. Gastrointest Cancer Res. 2008; 2:85-92.

4. Enzinger PC, Mayer RJ. Esophageal cancer. N Engl J Med. 2003; 349:2241-2252.

5. D'Journo XB, Thomas PA. Current management of esophageal cancer. J Thorac Dis. 2014; 6:S253-264.

6. Perez EA. Microtubule inhibitors: Differentiating tubulininhibiting agents based on mechanisms of action, clinical activity, and resistance. Mol Cancer Ther. 2009; 8: 2086-2095.

7. Dumontet C, Jordan MA. Microtubule-binding agents: a dynamic field of cancer therapeutics. Nat Rev Drug Discov. 2010; 9:790-803.

8. Jordan MA, Kamath K. How do microtubule-targeted drugs work? An overview. Curr Cancer Drug Targets. 2007; 7:730-742.

9. Jordan A, Hadfield JA, Lawrence NJ, McGown AT. Tubulin as a target for anticancer drugs: agents which interact with the mitotic spindle. Med Res Rev. 1998; 18:259-296.
10. Checchi PM, Nettles JH, Zhou J, Snyder JP, Joshi HC. Microtubule-interacting drugs for cancer treatment. Trends Pharmacol Sci. 2003; 24:361-365.

11. Pettersen EF, Goddard TD, Huang CC, Couch GS, Greenblatt DM, Meng EC, Ferrin TE. UCSF Chimera-a visualization system for exploratory research and analysis. J Comput Chem. 2004; 25:1605-1612.

12. Bayssas M, Gouveia J, de Vassal F, Misset JL, Schwarzenberg L, Ribaud P, Musset M, Jasmin C, Hayat M, Mathe G. Vindesine: a new vinca alkaloid. Recent Results Cancer Res. 1980; 74:91-97.

13. Rowinsky EK. The development and clinical utility of the taxane class of antimicrotubule chemotherapy agents. Annu Rev Med. 1997; 48:353-374.

14. Giannakakou P, Sackett D, Fojo T. Tubulin/microtubules: still a promising target for new chemotherapeutic agents. J Natl Cancer Inst. 2000; 92:182-183.

15. Kavallaris M. Microtubules and resistance to tubulinbinding agents. Nat Rev Cancer. 2010; 10:194-204.

16. Klute K, Nackos E, Tasaki S, Nguyen DP, Bander NH, Tagawa ST. Microtubule inhibitor-based antibody-drug conjugates for cancer therapy. Onco Targets Ther. 2014; 7:2227-2236.

17. Mollinedo F, Gajate C. Microtubules, microtubuleinterfering agents and apoptosis. Apoptosis. 2003; 8: 413-450.

18. Jordan MA, Wilson L. Microtubules as a target for anticancer drugs. Nat Rev Cancer. 2004; 4:253-265.

19. Vitale I, Galluzzi L, Castedo M, Kroemer G. Mitotic catastrophe: a mechanism for avoiding genomic instability. Nat Rev Mol Cell Biol. 2011; 12:385-392.

20. Tentler JJ, Tan AC, Weekes CD, Jimeno A, Leong S, Pitts TM, Arcaroli JJ, Messersmith WA, Eckhardt SG. Patientderived tumour xenografts as models for oncology drug development. Nat Rev Clin Oncol. 2012; 9:338-350.

21. Daniel VC, Marchionni L, Hierman JS, Rhodes JT, Devereux WL, Rudin CM, Yung R, Parmigiani G, Dorsch M, Peacock CD, Watkins DN. A primary xenograft model of small-cell lung cancer reveals irreversible changes in gene expression imposed by culture in vitro. Cancer Res. 2009; 69:3364-3373.

22. Walrath JC, Hawes JJ, Van Dyke T, Reilly KM. Genetically engineered mouse models in cancer research. Adv Cancer Res. 2010; 106:113-164.

23. Griggs J, Metcalfe JC, Hesketh R. Targeting tumour vasculature: the development of combretastatin A4. Lancet Oncol. 2001; 2:82-87.

24. Horsman MR, Siemann DW. Pathophysiologic effects of vascular-targeting agents and the implications for combination with conventional therapies. Cancer Res. 2006; 66:11520-11539.

25. Tozer GM, Kanthou C, Baguley BC. Disrupting tumour blood vessels. Nat Rev Cancer. 2005; 5:423-435. 
26. Zaninetti R, Cortese SV, Aprile S, Massarotti A, Canonico PL, Sorba G, Grosa G, Genazzani AA, Pirali T. A concise synthesis of pyrazole analogues of combretastatin A1 as potent anti-tubulin agents. ChemMedChem. 2013; 8:633-643.

27. Minotti AM, Barlow SB, Cabral F. Resistance to antimitotic drugs in Chinese hamster ovary cells correlates with changes in the level of polymerized tubulin. J Biol Chem. 1991; 266:3987-3994.

28. Prota AE, Danel F, Bachmann F, Bargsten K, Buey RM, Pohlmann J, Reinelt S, Lane H, Steinmetz MO. The novel microtubule-destabilizing drug BAL27862 binds to the colchicine site of tubulin with distinct effects on microtubule organization. J Mol Biol. 2014; 426: 1848-1860.

29. Berman HM, Westbrook J, Feng Z, Gilliland G, Bhat TN, Weissig H, Shindyalov IN, Bourne PE. The Protein Data Bank. Nucleic Acids Res. 2000; 28:235-242.

30. Schrödinger. Schrödinger Suite 2014. Schrödinger, LLC, New York, NY. 2014. 